Las Torres de Lucca. Revista internacional de filosofía política

ISSN-e: 2255-3827

\title{
Problemas de la participación política en contextos de desdemocratización ${ }^{1}$
}

\author{
Macarena Marey²
}

Recibido: 10-10-2021 / Aceptado: 20-12-2021/ Publicado: 30-01-2022.

Resumen. En este texto de presentación del número especial "Filosofía de la participación política", coeditado con Moira Pérez y Blas Radi, mapeo algunos de los temas y problemas que motivaron la convocatoria a trabajos. En la primera sección presento dos grandes modelos de la participación política en contextos democráticos, con la tesis de que los fenómenos desdemocratizantes del presente se ven facilitados por un cierto modo de entenderla. En la segunda sección propongo que una manera fructífera de estudiar la participación política es a través de los problemas que la inclusión en los procesos colectivos formales de decisión política democrática acarrea para determinadas personas y colectivos, en el marco de sistemas de dominación estructural. Por último, presento brevemente los diferentes trabajos que componen este número especial.

Palabras clave: democracia; dominación; injusticias; agencia política; resistencia.

\section{[en] Problems of political participation in contexts of de-democratization}

\begin{abstract}
In this introduction to the dossier "Philosophy of political participation", co-edited with Moira Pérez and Blas Radi, I map some of the topics and problems that motivated our call for papers. In the first section, I introduce two main models of political participation in democratic contexts, along with the thesis that a particular traditional way of understanding it promotes today's dedemocratizing phenomena. In the second section, I suggest that it is fruitful to study political participation by focusing on the problems that inclusion in collective formal processes of political decision causes for certain people and collectives, within the framework of systems of structural domination. In the last section, I briefly present the works collected in this dossier.
\end{abstract}

Keywords: Democracy; Domination; Injustices; Political agency; Resistance.

Cómo citar: Marey, M. (2022). Problemas de la participación política en contextos de desdemocratización, en Las Torres de Lucca. Revista internacional de filosofia política, 11(1), pp. 1-11. https://dx.doi.org/10.5209/1tdl.79868

Los mejores, los únicos, los métodos piqueteros / Corte de ruta y asamblea "Los métodos piqueteros", en Hasta las manos, Las manos de Filippi, 2002

En este texto de presentación del número especial "Filosofía de la participación política", coeditado con Moira Pérez y Blas Radi, mapeo algunos de los temas y problemas que motivaron la convocatoria a trabajos. En la primera sección presento dos grandes modelos de la participación política en contextos democráticos, con la tesis de que los fenómenos desdemocratizantes del presente se ven facilitados por un cierto modo de entenderla. En la segunda sección propongo que una manera fructífera de estudiar la participación política es a través de los problemas que la inclusión en los procesos colectivos formales de decisión política democrática acarrea para determinadas personas y colectivos, en el marco de sistemas de dominación estructural. Por último, presento brevemente los diferentes trabajos que componen este número especial.

Este trabajo se realizó con el financiamiento del proyecto PICT 2018-1575, "La noción de consentimiento en las teorías modernas del contrato social: cuestiones conceptuales y normativas”, Agencia Nacional de Promoción Científica y Tecnológica, Ministerio de Ciencia de la República Argentina.

2 Macarena Marey, Investigadora CONICET, directora del Núcleo de Estudios Críticos y Filosofía del Presente, Instituto de Filosofía, FFyL, UBA ORCID: 0000-0002-4826-0384

Las Torres de Lucca. 11 (1), 2022: 1-11 


\section{Modelos de participación en la toma política de decisiones en contextos democráticos}

Un modo tradicional de abordar la participación política en la filosofía contemporánea consiste en desplegar diferentes argumentos para justificar normativamente la participación ciudadana en la toma colectiva de decisiones. Generalmente, estos ejercicios filosóficos suelen contar como justificaciones de la democracia tout court, lo que da como resultado diferentes concepciones de la democracia-deliberativa, participativa, radical, agregativa, que a su vez se combinan con diferentes orientaciones ideológicas -socialismo, liberalismo, republicanismo-. La respuesta a la pregunta de por qué deberíamos participar en la toma colectiva de decisiones se asocia, en efecto, con una respuesta acerca de cómo solemos participar y hasta dónde y cómo deberíamos participar, lo que por su parte genera un modo determinado de comprender qué es y para qué queremos democracia y, sobre todo, a qué diseño institucional democrático específico debemos apuntar. Por ejemplo, la respuesta de Joseph Schumpeter (1942) produce un tipo de democracia agregativa, capitalista y con una participación acotada al voto (orientado, por su parte, a remover funcionarios) en la que la ciudadanía relega casi todo su juicio político en manos de expertos y políticos profesionales. Las respuestas de Iris Marion Young (2000, 2001, 2011) o Elizabeth Anderson (2010) generan una idea de democracia completamente diferente, que enfatiza la responsabilidad colectiva por las injusticias estructurales que persisten en todos los regímenes democráticos y la acción política extrainstitucional sin la cual esas injusticias se replican acríticamente en los procedimientos de toma de decisión, para imaginar prácticas democráticas institucionales en las que los públicos heterogéneos y la inclusión transformativa de los procesos de decisión y de sus resultados puedan promover relaciones sociales más justas.

Quiero concentrarme brevemente en estas dos concepciones de la participación política (necesariamente estilizadas aquí) porque considero que modelan con bastante fidelidad, respectivamente, una de las visiones más difundidas de lo político en nuestros presentes (la visión schumpeteriana de la democracia, como representante de la democracia capitalista en general) y una de las propuestas alternativas más eficaces para contrarrestar los fenómenos desdemocratizantes del mundo contemporáneo, aunque no exenta de sus propios problemas ella misma. Mi convicción es que los fenómenos desdemocratizantes ${ }^{3}$ del presente son posibilitados y facilitados e incluso a veces son epifenómenos de ese primer modo de pensar la participación política en democracia. Respecto de las soluciones y propuestas superadoras, la cuestión es como siempre más compleja, en gran medida porque los problemas de la participación política deben ser abordados dependiendo del contexto y de maneras no-ideales. El abordaje no-ideal en filosofía política normativa que tomo aquí sigue los lineamientos de Elizabeth Anderson (2010). ${ }^{4}$ El método no-ideal es muy pertinente para estudiar la participación política porque consiste, a grandes rasgos, en comenzar la teorización en filosofía política "desde un diagnóstico de las injusticias de nuestro mundo presente, antes que desde una imagen de un mundo ideal" (Anderson, 2010, p. 3). De este modo, el objetivo de la teoría no es proponer "principios e ideales para una sociedad perfectamente justa, sino los que necesitamos para habérnoslas con las injusticias de nuestro mundo actual y para movernos hacia algo mejor" (Ibidem). ${ }^{5}$ Una motivación importante para hacer teoría no-ideal es que la teoría ideal corre el riesgo de "saltar a la conclusión de que cualquier hiato entre nuestro ideal y la realidad debe de ser la causa de los problemas del mundo actual y que la solución tiene que ser, por lo tanto, adoptar políticas orientadas a cerrar esos hiatos" (Op. Cit, p. 4). La idea de que la realidad está en falta respecto de un ideal contribuye a mantener una actitud acrítica respecto de ese ideal, de su propio carácter de justo o injusto y de su pertinencia para los contextos prácticos concretos. En pocas palabras, analizar el presente con una teoría ideal obstaculiza el reconocimiento de las injusticias de nuestro mundo (Op. Cit., p, 5), que es no-ideal por definición.

El objetivo principal de Capitalismo, socialismo y democracia de Schumpeter era refutar la idea de que el socialismo pertenecía al "club democrático" (Schumpeter, 1942, p. 235), para lo cual también se propuso refutar las teorías modernas del contrato social, que consideraba responsables de las ideas de bien común y de la voluntad unida del pueblo. Schumpeter ataca especialmente las nociones de pueblo, demos, voluntad general

Entiendo la desdemocratización como una tendencia inherente a los regímenes democráticos capitalistas, por la cual las instituciones políticas, jurídicas, económicas y sociales tienden a restringir el acceso a la participación política efectiva y a la igualdad material digna. De este modo, los fenómenos desdemocratizantes no son exógenos a esos contextos y no pueden ser enfrentados si no se los entiende como rasgos estructurales de ellos. De ahí que una política que se oriente a contrarrestar tales fenómenos debería apuntar a la transformación de las estructuras de dominación. La literatura sobre los fenómenos contemporáneos desdemocratizantes, sobre todo neoconservadores, es inabarcable. Para varios estudios sobre los fenómenos desdemocratizantes en América y el Caribe hoy, recomiendo Ailynn Torres Santana, (ed.), Derechos en riesgo en América Latina. 11 estudios sobre grupos neoconservadores, Quito, Fundación Rosa Luxemburgo, 2020.

4 Anderson aplica la teorización no-ideal al racismo estructural de los Estados Unidos, analizando las diferentes luchas contra él en ámbitos jurídicos e institucionales (véase sobre todo el capítulo 5, "Ideales democráticos y segregación"), para a partir de este análisis llegar a una teoría de la democracia que hace énfasis en la idea de democracia como organización de membresía y forma de gobernanza y cultura. A partir de esto, Anderson desarrolla una visión de la integración (por contraposición a segregación) que consiste en "la interacción libre de ciudadanos de todas las procedencias en términos de igualdad y consideración en todas las instituciones de la sociedad civil y en términos voluntarios en las asociaciones íntimas de la vida privada", que da cuenta de los "tres grandes temas de la teoría democrática: indagación colectiva, rendición de cuentas e igualdad" (Anderson, 2010, p. 95). Véase también Radi, (2021), pp. 5-8, para una explicación del método no-ideal, que él aplica a un análisis de los obstáculos que las personas trans enfrentan para acceder al goce de derechos subjetivos sancionados por los sistemas legales.

En este sentido la metodología no-ideal es asimilable a los universalismos situados. 
y bien común y orienta sus críticas a delimitar un círculo muy pequeño de racionalidad y acervo cognitivo en la acción humana, i. e., la esfera de "familiaridad". Esta esfera contiene

la mayoría de las decisiones de la vida cotidiana que se encuentran dentro del reducido terreno que la mente del ciudadano individual abarca con un sentido pleno de su realidad. A grandes rasgos, consiste en las cosas que le incumben directamente, su familia, sus asuntos de negocios, sus hobbies, sus amigos y enemigos, su municipio o distrito, su clase, su iglesia, sindicato o cualquier otro grupo social del que sea un miembro activo -las cosas que están bajo su observación personal, las cosas que le son familiares independientemente de lo que le diga su diario, las cosas que puede manejar o sobre las que puede influir directamente y para las cuales desarrolla el tipo de responsabilidad que se induce de una relación directa con los efectos favorables o desfavorables de un curso de acción (Schumpeter, 1942, pp. 258-259).

Así como está descrita en el pasaje citado, el alcance de la familiaridad parece amplio e incluso se aventura en terrenos stricto sensu políticos y colectivos (como sindicatos e iglesias). Sin embargo, el punto que quiere hacer Schumpeter es que en las democracias de masas las personas comunes y corrientes deben ser alejadas lo más posible de los lugares en los que se toman esas mismas decisiones políticas que afectan colectiva y directamente las cuestiones familiares, de negocios, sindicales, de clase y eclesiásticas sobre las cuales estas personas sí tomarían decisiones (más o menos plenamente) racionales. Por fuera de esta esfera de familiaridad, de hecho, los ciudadanos deberían dejar todo en manos de políticos expertos, pues "el ciudadano típico cae a un nivel inferior de rendimiento mental tan pronto como ingresa en el terreno político. [...] Su razonamiento se vuelve asociativo y afectivo" (Schumpeter, 1942, p. 262).

Creo que no es arriesgado afirmar que esta visión de la participación política ha calado bastante profundo hasta volverse sentido común en varios discursos cotidianos y públicos y en varios contextos políticos. Se trata de una concepción desdemocratizante de la democracia que se basa en, al menos, las siguientes ideas. En primer lugar, las personas seríamos generalmente ignorantes de los grandes temas sobre los que versan las jurisdicciones pública, política y económica. Al ser estos temas cuestiones con las que las personas mantendríamos una relación más abstracta que con nuestro ámbito cotidiano (aunque esas mismas cuestiones son las que a fin de cuentas definen nuestras vidas cotidianas), perderíamos el sentido de realidad y por lo tanto de responsabilidad por esas decisiones y nos volveríamos, así, presa fácil de motivaciones irracionales y eminentemente emocionales en el momento de tomar decisiones. Esto nos haría a su vez proclives a caer en la manipulación de la demagogia más burda, lo que pronunciaría nuestra irracionalidad e ignorancia. ${ }^{6}$

Esta teoría de la racionalidad humana acotada es, a mi juicio, poco más que una abstracción teórica del recelo frente al pueblo, los movimientos populares, las personas y colectivos históricamente marginalizados de la participación política por cuestiones de clase, género, "raza", origen geográfico y estatuto migratorio en general. Ahora bien, el problema aquí no es solamente que exista un miedo, sincero o no, frente a la irracionalidad por causa del cual se necesite ponerle límites a la adscripción de racionalidad-como si la racionalidad no incluyera el error en su mismo funcionamiento. Se trata de que esta concepción de la racionalidad está idealizada en dos sentidos. Uno de ellos es la reducción de su rango de acción, por la que se la limita a un ámbito determinado de la vida social, privatizándolo. El otro, su atribución limitada con exclusividad a ciertos actores sociales, con la consecuente negación de esa racionalidad a otras subjetividades y modos de agencia. Con esta idealización de la racionalidad humana se asocia, además, la idea de que los colectivos humanos tienden a convertirse en turbas que "queman brujas" y aplastan toda disidencia. En resumen, la racionalidad humana idealizada en esta visión de lo social es similar a la del tradicional maximizador global que actúa con precisión y certeza solamente cuando se guía por su autointerés y que consigue departamentalizar exitosamente diferentes aspectos de su vida práctica en diferentes esferas privadas.

Esta reducción de la racionalidad a la individualidad se conecta asimismo con dos tesis que guardan una relación directa con el modo en el que se entiende la participación política. Por un lado, la desvaloración de la afectividad/emotividad en la política descansa sobre la ilusión de que un agente maximizador global es idealmente inmune a la emotividad y los afectos en el ámbito de sus elecciones autointeresadas o, lo que es casi lo mismo, que ser un individuo autointeresado capaz de, por ejemplo, privatizar su religiosidad no implica ya por sí mismo un tipo muy determinado de afectividad. Por el otro, colabora para producir la tesis paradigmáticamente planteada por Benjamin Constant (1819) y luego radicalizada por Isaiah Berlin (1958) de que existe una dicotomía ético-política entre libertad individual y negativa, por un lado, y libertad política y positiva, por el otro, con la valoración positiva de la primera y negativa de la segunda. En efecto, la tesis constantiana incluye la idea de que la libertad contemporánea se define en gran medida por el tiempo y la responsabilidad que insumen a todos los individuos las actividades económicas, a diferencia de la libertad

Otra manera de des-agenciar en este sentido bastante en boga en teorías y discursos políticos es afirmar que las militancias partidarias políticas solo son (cuando el partido político no es aquel con el que simpatiza quien formula esta crítica) una adicción acrítica a un líder que manipula a sus seguidores. En su sexto ensayo en el libro Siete ensayos sobre el populismo, Paula Biglieri y Luciana Cadhia (2021) sostienen que el surgimiento de un líder no puede ocurrir sin la acción organizada de movimientos sociales, gremios y militancias. La acción y el juicio políticos de las y los militantes no están formados unilateralmente por las directivas del líder partidario sino que esa constitución es recíproca. 
antigua que dependía por entero de la delegación de esas actividades en manos de personas esclavizadas. ${ }^{7}$ Esta dicotomía (nuclear del liberalismo) se asienta sobre otra distinción agonista tajante que organiza esta visión de lo político: individuos y familias, por un lado, versus gigantescos colectivos homogeneizantes y aplastadores de diferencias, por el otro. De ahí la insistencia en separar al pueblo del Estado y la insistencia en que en rigor no hay una entidad ontológica asimilable a "pueblo" (algo que la democracia radical, el republicanismo de izquierdas, el socialismo y el populismo tampoco afirman, dicho sea de paso). ${ }^{8}$ Por detrás de esto está la intención de establecer que la única dominación realmente peligrosa es la que pueden ejercer el Estado y el pueblo por sobre el individuo y su familia y no las formas de dominación propias de las relaciones sociales asimétricas.

Lo que me interesa resaltar es que la reducción de la racionalidad a la individualidad y de su jurisdicción al ámbito estricto de la familiaridad inmediata (con su contracara, la tesis epistócrata de que no puede haber racionalidad en los colectivos humanos politizados) ${ }^{9}$ viene aquí de la mano junto con la desdemocratización de la mayoría de los lugares de toma de decisión. Podemos decir, siguiendo a Ellen Meiksins Wood (1995), que este distanciamiento respecto de los lugares de toma de decisión es un movimiento clave de la apropiación capitalista del concepto de democracia. La limitación estrecha de la participación política a momentos esporádicos del funcionamiento democrático (el voto) está cargada, así, ideológicamente con una concepción determinada acerca de quién es el sujeto de la política, acerca de qué tipo de personas tienen derecho a una participación política plena y quiénes no. En nuestros contextos políticos concretos, podemos ver este movimiento marginalizante en la criminalización de la protesta social.

No toda protesta política, no toda marcha, corte de ruta, asamblea popular, toma de edificios públicos o manifestación callejera, no toda militancia ni todo activismo son criminalizados en un mismo contexto dado. En cada contexto, ¿qué protestas sociales se permiten y cuáles se castigan, qué tipo de subjetividades, actores y movimientos son premiados por su protesta y cuáles castigados por su mera aparición en escena? En más casos que en menos, las formas de protesta llevadas a cabo por actores sociales marginalizados históricamente de la participación política institucional y cuyo objetivo inmediato y concreto se enmarca en un futuro de transformación de las injusticias estructurales son usualmente reprimidas y perseguidas por las fuerzas represivas del Estado, por los medios de comunicación que se encargan de estigmatizar a sus protagonistas y a sus demandas e incluso por actores paraestatales que ejercen diferentes tipos de violencia, incluidos el asesinato y la desaparición de personas. Por el contrario, quienes históricamente han protagonizado la vida institucional de los Estados al protestar políticamente no se rebelan contra un orden establecido, pues aunque afirmen, por ejemplo, que la ampliación de derechos para las personas LGBTIQ+, los derechos sociales y los impuestos progresivos son medidas dictatoriales que los oprimen, no buscan en rigor una modificación de las relaciones sociales para que estas resulten menos injustas. Su manifestación pública está motivada por el miedo a perder los privilegios que les da ese orden establecido que ven amenazado por la militancia y activismo de actores políticos generalmente marginalizados. Estas protestas reactivas no son, usualmente, criminalizadas; por el contrario, son premiadas con un protagonismo mediático y discursivo que marca la agenda política, económica y social en detrimento de la mayoría del demos. La criminalización de la protesta social puede ser teorizada también como un efecto de la tesis de que la racionalidad necesaria para la agencia política la conservan solo un tipo de personas, i. e., esas personas que si bien siempre protagonizaron la política, solo irrumpen disruptivamente en la escena de la protesta cuando sus privilegios son puestos en cuestión, sea por el Estado mismo, sea por movimientos políticos y sociales o por la "amenaza" que les plantean la mayor presencia visible de otros agentes políticos y sociales y la convivencia democrática.

Pareciera, así, que el problema principal a solucionar si queremos sociedades democráticas más justas es la inclusión y la integración de otros tipos de agencia y actores en el modo de concebir la participación política. Iris Marion Young es una de las filósofas que más ha aportado a la reflexión sobre la participación política en la democracia desde el punto de vista de la inclusión de las personas marginalizadas en los mecanismos de toma de decisión. De manera esquemática, la propuesta de Young para la participación democrática puede ser resumida como sigue. El punto de partida de Young es un diagnóstico crítico sobre la participación política en las democracias existentes que la ubica en la línea de la teoría no ideal:

La tesis (que quiere ser empírica y normativa) sobre la relación entre esclavitud y libertad política en Constant es doblemente falsa, no solo porque no es cierto que en 1819 no existiera la esclavitud sino que además no es cierto que los hombres ricos que no trabajaban fueran los únicos actores políticos en la antigüedad clásica. María Julia Bertomeu señala que "gran parte del trabajo [en la Grecia antigua] lo hacían los pobres libres, aquellos a los que la democracia de Ephialtes les dio la palabra en el ágora”. La tergiversación sobre la riqueza de los ciudadanos libres estaba diseñada "para cargar las tintas de la dominación en la política y así ocultar la dominación en el ámbito privado" (María Julia Bertomeu, 2021, intercambio personal). Véase asimismo Rosenberg (2006) pp. 46-47: “en la antigüedad [...] junto a los esclavos fueron también numerosísimos los siervos de la gleba, pero aún en número mayor, hubo proletarios libres. [...] [N]o es precisamente la lucha de clases entre libres y esclavos la que desempeña el papel determinante. Otros conflictos sociales poseyeron un alcance mucho más decisivo".

La artificialidad de lo político y la politicidad de "pueblo" son tesis centrales de varias tradiciones políticas de izquierdas y se remontan a las teorías modernas del contrato social. Por ejemplo, Biglieri y Cadahia (2021) muestran que la negación de la prepoliticidad identitaria del pueblo es uno de los rasgos centrales del populismo.

Para una crítica sólida contra las objeciones epistócratas contra la participación ciudadana en términos de una defensa epistémica y participativa de la democracia deliberativa, véase Lafont (2019). 
en el mundo real algunas personas y grupos tienen una habilidad significativamente mayor para usar los procesos democráticos para sus propios fines mientras que otras personas y grupos son excluidos o marginalizados. Nuestras discusiones sobre políticas democráticas no ocurren en condiciones libres de coacción y amenaza ni libres de la influencia distorsiva del poder y control desigual sobre los recursos. En las democracias realmente existentes tiende a haber un círculo de mutua promoción entre la igualdad social y económica y la igualdad política que les posibilita a los poderosos usar los procesos formalmente democráticos para perpetuar la injusticia y preservar privilegios (Young, 2000, p. 17).

Young propone que para romper este círculo vicioso es necesario ampliar y profundizar la inclusión en la participación política. La inclusión política que propone Young se orienta a producir un "público heterogéneo comprometido con transformar las instituciones sociales para hacerlas más efectivas para la resolución justa de problemas compartidos" (p. 12). El objetivo de la inclusión en la participación es, así, el de producir resultados más justos que a su vez repercutirán sobre las desigualdades estructurales para transformarlas. Para esto, Young propone su propio ideal de la democracia deliberativa, un modelo comunicativo de la política institucional en el que los actos participativos son mucho más amplios que los del limitado intercambio de argumentos racionales de manera ordenada. Si bien esto la expone a los problemas que genera la confianza en los procedimientos deliberativos, por más amplios que sean, y en su capacidad para transformarse a sí mismos en escenarios más justos, el criterio operativo de Young es teorizar la inclusión en términos de una crítica a los efectos perniciosos de la exclusión y la marginalización políticas. Por esto señala que es importante no usar "exclusión" e "inclusión" para hablar de cualquier tipo de conflicto social e injusticia: "Cuando los problemas son el racismo, la intolerancia cultural, la explotación económica o la negativa a ayudar a personas en necesidad, deben ser así llamados" (Young, 2000, p. 13), y no equiparados con la exclusión política tout court. Esta indicación es acertada, pero también significa que porque son problemas diferentes (o mejor, aspectos diferentes de las mismas injusticias estructurales) la mera inclusión política en los procesos formales de toma de decisión colectiva no es suficiente para superar esas injusticias sociales.

La confianza de Young en su modelo de participación inclusiva y en los efectos que ella puede tener en las relaciones sociales es, quizás, demasiado grande: la participación incluyente en los procesos democráticos institucionales es ella misma problemática, ella misma genera problemas nuevos que se suman a las desigualdades iniciales, sobre todo cuando hay racismo, intolerancia cultural, explotación económica e indiferencia hacia quienes están en necesidad. Además, la inclusión en los procesos de toma de decisión no responde directamente a la cuestión de la participación en la determinación de la agenda política y legislativa, anterior a la puesta en marcha de los procesos institucionales de toma de decisión. Los procesos colectivos de decisión pueden ser entendidos como situaciones dentro de situaciones, en las cuales los problemas no solo pueden reflejarse y reproducirse, sino que puede ocurrir que surjan nuevos problemas que afecten las vidas de esas personas por cuya inclusión aboga la propuesta de Young. Blas Radi (2021) ha mostrado de qué modo la confianza excesiva en la integración institucional y estatal genera inconvenientes ulteriores para las personas que se supone se están incluyendo con esa integración. Radi nota que "[a]unque la irrupción de personas trans en ámbitos de los que han sido históricamente excluidas es sin dudas algo significativo, eso no significa que la participación política esté garantizada" (Radi, 2021, p. 77). Esta inclusión se ha dado en general, explica Radi, de manera meramente agregativa, sin apuntar a la modificación de las dinámicas y estructuras internas de esos espacios. Esta lógica inclusiva agregativa

da por hecho que lo único que falta para alcanzar la justicia es que un puñado de integrantes de ciertos grupos sociales tengan un lugar en conversaciones institucionales (aunque sea a modo de miembrx no participante). Esto supone una inversión teleológica, porque la inclusión se revela como un fin en sí mismo, algo que le permite cumplir (por lo menos formalmente) con el rol legitimador de la participación, pero que no resulta suficiente para cumplir con su rol instrumental. Máxime teniendo en cuenta que, a menudo, la inclusión se interpreta como signo inequívoco de justicia social, que se proyecta sobre los procedimientos y los resultados $\mathrm{y}$, por lo tanto, no incluye mecanismos de monitoreo y rendición de cuentas (Radi, 2021, p. 78). ${ }^{10}$

Young (2001) misma reconoce estos problemas: entrar en escenarios deliberativos y ponerse a deliberar no siempre es una posibilidad real para muchas personas e incluso no siempre es el curso de acción política indicado y deseable. ${ }^{11}$ Por estos motivos, la inclusión en procesos democráticos tiene que ser tal que modifique los términos en los que esos procesos son conducidos. El problema más difícil de resolver es, claramente, cómo se logra esto y aquí es donde está el secreto de la participación política.

Cuatro son los elementos centrales que hacen atractiva a la propuesta de Young, allende sus propios inconvenientes. En primer lugar, resalta la importancia de las instituciones estatales como herramientas para el cambio social y aboga por la participación institucional, no meramente en la sociedad civil; es decir, se trata de

\footnotetext{
La propuesta de Radi es enfatizar el rol político de la intransigencia (Radi, 2021, p. 82).
}

Traté este tema en Marey (2012). 
una propuesta política que no privatiza ni ONGeniza la acción social sino que puede reconducirla políticamente para que tenga resultados institucionales concretos. En segundo lugar, propone un modelo de participación en varios niveles que debe combinar necesariamente instancias regionales e instituciones participativas barriales y organizadas por afinidades grupales, siguiendo la lógica de lo que ella llama "solidaridad diferenciada". En tercer lugar, la inclusión política no es un fin en sí misma, es una condición para la transformación de los términos y del estilo del debate público, lo que a su vez es condición necesaria para un cambio concreto y significativo en sus resultados. En cuarto lugar, y quizás de manera más importante, un rasgo interesante de la propuesta de Young consiste en que permite disolver la dicotomía falsa entre autointerés y bien general, con lo que podemos dar un paso importante para una teorización normativamente más adecuada de la participación política en democracia. Su "modelo comunicativo de la inclusión democrática teoriza segmentos sociales diferenciados que entran en conflicto y se involucran unos con otros a través de sus diferencias antes que poniendo esas diferencias de lado para invocar el bien común" (Young, 2000, p. 18). Esto constituye una visión de la política alternativa a la oposición entre la política como competencia de intereses privados en pugna versus el llamado a dejar de lado los intereses particulares. En esta "tercera posibilidad" para entender la participación política, a mi modo de ver mucho más realista, el debate y la toma democrática de decisiones se entienden

como un proceso en el que grupos sociales diferenciados deben atender a las situaciones particulares de otros y estar dispuestos a llegar a soluciones justas para sus conflictos y problemas colectivos desde sus posiciones situadas. Es un error considerar la afirmación de experiencias de personas ubicadas en grupos sociales estructural o culturalmente diferenciados como nada más que la afirmación de un interés autorreferencial. Esta mala interpretación se deriva en parte de un error de comprensión de esas expresiones públicas grupales únicamente como afirmaciones de una "identidad” grupal (Young, 2000, p. 7).

Sin embargo, lo que suele estar obturado en nuestros contextos democráticos es la posibilidad misma de que los intereses grupales de muchos colectivos sean escuchados por los grupos que dominan la participación, de que sean comprendidos si son escuchados y de que si son comprendidos esas demandas les importen a quienes dominan la participación. El punto, a mi juicio, es que las injusticias estructurales en cuyo marco tenemos que pensar la participación política están siempre por detrás y por debajo del conflicto: el conflicto tiende a invisibilizarlas con su presupuesto de igualdad de las partes.

\section{Dominación, resistencia y agencia política}

Los tipos de argumentos para justificar los modos de participación política generan varias combinaciones posibles, diferentes modulaciones de las concepciones de la democracia: existen, así, justificaciones epistémicas de la democracia agregativa (la línea abierta paradigmáticamente por Condorcet, 1785), justificaciones epistémicas de la democracia deliberativa, justificaciones morales de la democracia participativa y todas las combinaciones que se puedan armar. Pero no es la justificación de la participación política lo que interesa principalmente aquí. Participamos en los procesos de decisión política simplemente porque, en una democracia, la responsabilidad por esas decisiones recae en términos ideales en la ciudadanía. Asumiendo, entonces, no solo que la participación colectiva en la toma de decisión política es necesaria y que en varios de nuestros contextos es considerada justificada y hasta está moralizada, importa estudiarla en términos de los problemas, las dificultades, obstaculizaciones, marginalizaciones y los costos excesivos que las formas tradicionales, institucionales o no, de participación política en nuestras democracias tienen para la mayoría de las personas, aquellas generalmente para quienes las decisiones políticas estatales tienen una influencia en sus vidas mucho mayor que su propia capacidad para influir en los resultados de los procesos institucionales de toma de decisión.

Si nuestro objetivo es pensar de qué modo instrumentar una participación política significativa que tenga éxito en modificar las condiciones injustas mismas desde las que se participa, un principio crítico para guiarnos puede ser que la política y lo político no tratan simplemente del conflicto entre intereses egoístas irreconciliables (visión que da forma a la participación acotada al voto), entre diferentes planes acerca de cómo debe hacerse algo o entre visiones multiculturales diferentes del mundo (visión que da forma a la democracia deliberativa liberal del tipo rawlsiano o habermasiano). Lo que se pone en juego en última instancia en la toma política de decisión es una dimensión estructural previa al conflicto y que muchas veces las teorizaciones sobre el conflicto (sea que propongan el consenso como fin de la política, sea que piensen el conflicto como constitutivo de lo político) ocultan: la dominación.

Tomo aquí la idea de dominación en el sentido en el que la tomó Charles Mills en su obra El contrato racial para pensar la supremacía blanca como sistema político que estructura material, moral y epistémicamente el mundo, cuyo objetivo es "privilegiar diferencialmente a las personas blancas como grupo respecto de las personas no-blancas como grupo, explotar sus cuerpos, tierras y recursos y negarles oportunidades socioeconómicas iguales" (Mills, 1997, p. 11). Los sistemas de dominación (como por ejemplo el racismo, 
el imperialismo, el sexismo, el cissexismo, que a su vez se entrecruzan $)^{12}$ tienen un efecto especialmente pesado sobre la participación política en la medida en que no solamente marginalizan voces sino que además despliegan mecanismos epistémicos y morales cuyo objetivo es evitar que los problemas concretos de las personas marginalizadas de la participación política sean tomados en cuenta en el diseño de políticas públicas y en la legislación.

El principio de la dominación es una guía útil para la praxis y nos permite apreciar, por ejemplo, lo acertado de esta indicación de Lynn Sanders: "Si la dominación en las discusiones entre grupos no es atribuible a habilidades superiores en cuanto al razonamiento, argumentación o deliberación por parte del grupo dominante, entonces no es probable que distribuir las habilidades para la deliberación de manera más amplia vaya a solucionar los problemas de participación o influencia desiguales. En vez de esto, mejorar la discusión democrática parece requerir intervenciones en la estructura de las deliberaciones grupales" (Sanders, 1997, p. 366, resaltado mío). Tener en cuenta que si el conflicto es el piso de la política, la dominación es el subsuelo es provechoso también para problematizar las diferentes instancias de la participación política sin recaer en una teorización que termine por equiparar, por ejemplo, las protestas sociales antiigualitarias reactivas y las igualitarias. En efecto, el activismo disruptivo y el discurso de la rebeldía y el desacato pueden ser igualmente asumidos por grupos cuyos idearios son directamente contrarios a los principios normativos de la democracia. Robert Talisse nota acertadamente que

[...] no todos los activistas son progresistas [...]. Los activistas de extrema derecha racista también afirman estar peleando por la justicia, la equidad y la liberación. Sostienen que los procesos e instituciones existentes son ideológicamente hegemónicos y distorsivos. Consistentemente, rechazan cualquier ideal deliberativo por las mismas razones que el activista de Young [i. e., activista que combate injusticias estructurales y se orienta de manera inclusiva/progresista/de izquierdas]. [...] Lo que es más importante, consideran al vocabulario de "inclusión", "desigualdad estructural", "poder institucionalizado" del activista de Young como completamente en línea con lo que ellos afirman que es una ideología hegemónica que actualmente domina y distorsiona sistemáticamente nuestros discursos políticos (Talisse, 2005, pp. 436-7).

Todos los actores políticos, incluyendo los protagónicos, pueden recurrir a estrategias participativas disruptivas e incluso denunciar que el discurso de las injusticias estructurales y de la dominación es hegemónico, como de hecho hacen hoy en día varios partidos políticos conservadores y de derechas en diferentes países, intelectuales en los foros públicos y semipúblicos, personas en las redes sociales y contramovimientos varios, incluyendo el feminismo transexcluyente. En pocas palabras, el llamado de atención es pertinente: el locus de la rebelión contra la opresión (de la desobediencia civil y de la lockeana apelación al cielo) es usado con frecuencia creciente por actores políticos de derecha extrema.

Este punto nos llama la atención sobre la necesidad de pensar la participación política como una práctica que está siempre situada de manera dinámica en un entramado de relaciones sociales (no ya en una identidad prepolítica fija que se piense como necesariamente buena o mala), ${ }^{13}$ por un lado y, por el otro, sobre la necesidad de pensar el carácter instrumental de la participación política. Coincido con Elster en que la participación política es un tipo de actividad que adquiere su razón de ser cuando está orientada a un fin externo a la mera acción de participar, sea cual fuere esta acción (manifestación, presentarse a elecciones, hablar en el Parlamento, etc.). La política debe tratar sobre algo ${ }^{14}$ de modo que la acción de participar tiene sentido con vistas a la toma de decisiones concretas sobre ese algo, decisiones que afectarán la vida de las personas. En marcos democráticos, la participación política es un medio orientado a un fin político, social, colectivo y económico democrático, no meramente un fin en sí mismo que no se pueda evaluar y criticar a su vez externamente, con criterios democráticos de justicia respecto de la adecuación entre la acción de participar y los objetivos por ella esperados y respecto de la relación entre los efectos realmente conseguidos por ella y los principios críticos y normativos democráticos. En la Argentina se suele escuchar la queja reactiva "apoyo el reclamo, pero no los métodos" cuando un movimiento piquetero o un grupo de trabajadores corta una calle (pero muy pocas veces cuando un grupo de poder económico corta una ruta). Es importante señalar, contra esta tendencia a objetar la participación política disruptiva cuando la llevan a cabo ciertas personas y colectivos y no cuando lo hacen otros, que ningún método de participación política, desde el voto hasta la toma de un edificio público, pasando por las intervenciones orales ordenadas de legisladores en los Parlamentos, garantiza por sí mismo la legitimidad democrática de su reclamo concreto.

12 El republicanismo de izquierdas (socialista, radical o democrático plebeyo) también entiende que la dominación es estructural y no una mera situación pasajera entre dos individuos considerados de manera aislada de las relaciones sociales, la historia y las instituciones. Particularmente, enfatiza la relación entre dominación, estatalidad y propiedad privada. Entender la dominación como un fenómeno estructural nos permite explicar la injusticia de las desigualdades materiales y de concentración de la propiedad privada de los medios de la producción, sin obligarnos a asumir una concepción pettitiana negativa de la libertad como no-dominación. Véase al respecto de María Julia Bertomeu (2021).

Para una crítica certera a las denominadas "políticas de identidad”, véase Pérez, 2021.

14 Elster, 1986, p. 149: "Es inconsistente valorar la participación política si no es sobre algo." 
Por otro lado, si no se orienta a un fin colectivo externo al acto participativo mismo, ese acto difícilmente tenga un efecto transformativo en la toma de decisión política. El efecto inmediato de perder de vista el carácter orientado a la transformación de la participación política, i. e., de desconectar la participación de los criterios normativos democráticos y volverla un fin en sí misma sin mayor reflexión sobre sus efectos en las vidas de las personas que suelen ser marginalizadas de los espacios institucionales, es la despolitización del acto de participar, su privatización y su deslizamiento hacia la inversión de los medios estratégicos por los fines o principios normativos de la democracia. El efecto global de esta desconexión es el refuerzo de injusticias estructurales.

En resumen, tanto el conflicto como la dominación y su comprensión en términos situados en las relaciones sociales, por contraposición a un abordaje teórico "imparcial", son elementos imprescindibles para estudiar la participación política como práctica orientada a un fin político externo a ella misma. En el marco crítico aquí esbozado, este fin no es el mero consenso. En lugar de tomar el arribo al consenso como fin último de la participación política en los procesos democráticos de toma de decisión, una teoría de la participación política que sea sensible a las injusticias estructurales entiende que el imperativo del consenso genera sus propios problemas cuando es tomado como el télos de los procesos de decisión colectiva. En palabras de Elizabeth Anderson, "condicionar decisiones al logro del consenso con frecuencia conduce a una presión excesiva e incluso a la coerción sobre minorías que disienten" (Anderson, 2010, p. 16). El consenso tiene que estar él mismo orientado a la transformación de las injusticias estructurales y no esta supeditada al acuerdo.

Por último, quisiera mencionar otros dos conceptos fundamentales para una filosofía de la participación política: la pregunta por la agencia política y el problema relacionado con esta de los costos que una idealización de los modos de la agencia política puede traer a las personas. Respecto de la agencia política, se podría pensar que la marginalización en los contextos de sistemas de dominación des-agencia de manera absoluta a esas personas marginalizadas del protagonismo político institucional, pero se estaría en un error. No todas prácticas con efectos sociales y políticos transformadores son necesariamente intencionadas como acciones de participación política institucional, incluso algunas no son concebidas como participación política en primer lugar.

En el capítulo 6 de Teoría feminista. De los márgenes al centro ("Cambiando las perspectivas sobre el poder"), bell hooks critica los modos en los que ciertos discursos feministas blancos abordan el tópico del poder en términos dicotómicos (hombres poderosos, mujeres vulnerables), lo que las lleva en la práctica a ejercer el poder en términos de dominación que replican y refuerzan el sistema racista, patriarcal y capitalista, en lugar de crear nuevos sistemas de valores en los que el poder no se cifre en doblegar a otras personas. Contra esto, bell hooks sostiene que "[1]a sugerencia de que las mujeres tienen que obtener poder antes de que puedan resistir el sexismo de manera eficaz se funda en la presuposición falsa de que las mujeres no tienen poder. Las mujeres, incluso las más oprimidas entre nosotras, sí ejercen algún poder" (hooks, 1984, p. 92). Para poder reconocer en las vidas y en las prácticas de las mujeres ese poder capaz de reconceptualizar el poder como dominación, hay que observar a las mujeres trabajadoras, las mujeres racializadas y a las mujeres pobres. El feminismo hegemónico burgués, sostiene hooks, es incapaz de reconocerlas como modelos de poder porque las formas de poder que ejercen no son valoradas en esa sociedad (hooks, 1984, p. 89). Cambiar la perspectiva sobre el poder permite encontrar un poder concreto y eficaz en la agencia propia que de otro modo permanecería oculto. Un ejemplo que rescata hooks en este texto es el poder de las mujeres como consumidoras a cargo de las compras del hogar. Este deslizamiento del rol de organizadora de la economía familiar y consumidora de moda desde un lugar subalternizado a un lugar de poder permite trazar estrategias de lucha política por medio de la organización colectiva de ese poder, que preexiste de manera no dominadora, en boicots.

Las prácticas éticas y sociales transformativas muchas veces existen ya como prácticas de no-dominación que escapan a las dinámicas agonistas de lo político (pienso por ejemplo en un comedor comunitario popular, en la organización barrial de las tareas de cuidado) y una buena teoría de la participación política debería hacer lugar para la posibilidad de modos de agencia que exceden el marco conceptual opresión-resistencia y sus presupuestos voluntaristas sobre la acción intencional.

En Políticas de la piedad, Saba Mahmood emprende varias tareas filosóficas. La más importante de ellas, a mi juicio, es la reflexión ética y política sobre la agencia en términos que superan la oposición totalizante opresión versus resistencia y los postulados sobre la subjetividad que esta tiende a llevar consigo. Sus complejos análisis etnográficos sobre el movimiento pietista de mujeres en las mezquitas de El Cairo entre 1995 y 1997 visibilizan conceptualmente modos de agencia que tienen efectos políticos contestatarios o emancipadores pero cuyas prácticas y acciones no se conciben como orientadas a la emancipación, en gran medida porque no intentan conscientemente ser respuestas a formas de dominación sino que son prácticas desarrolladas a partir de la experiencia de las necesidades y deseos propios. Estas mujeres se organizaron en sesiones de clases de religión impartidas por mujeres expertas en esos temas en mezquitas de diferentes zonas y condiciones sociales de El Cairo, para educarse en aspectos religiosos del islam que ellas no conocían y que estaban tradicionalmente bajo el dominio de los hombres. Los efectos de este movimiento, intencionados o no, incluyeron el empoderamiento de las mujeres en cuestiones religiosas en sus ámbitos familiares en un contexto en el que la religión regula la mayoría de la normatividad y una obstaculización a los modos capitalistas e imperiales de subjetivación. En su 
prólogo a la edición de Políticas de la piedad de 2012, Saba Mahmood resalta la participación de las mujeres del movimiento de la piedad en las manifestaciones de la llamada Primavera Árabe en 2011 y una afinidad entre este movimiento de mujeres musulmanas y las demandas democráticas en general, afinidad promovida en gran medida por la conciencia que este movimiento ganó de que la democracia y los derechos sociales no ponen en peligro esas prácticas religiosas que ellas tomaron en sus manos y que además pueden resguardarlas. En resumen, la participación política puede asumir formas de agencia que no se pueden describir ni comprender cabalmente en términos de resistencia a la dominación y en términos de acción exclusivamente política, pero cuya eficacia política y social para la erosión de los sistemas de dominación puede ser mayor a los modos tradicionales de militancia política.

Toda participación política tiene un costo. Es irrealista diseñar utopías en las que las acciones humanas no impliquen costos, externalidades, pérdidas y conflictos. Pero para algunas personas los costos son innecesaria e injustamente altos. Es importante entonces detectar modos de participación política efectiva y significativa cuyo costo no acarree para las personas que participan un afianzamiento, agravamiento o perpetuación de las injusticias estructurales que las afectan. Para conseguir esto, Moira Pérez propone evaluar los métodos de participación por medio de un equilibrio reflexivo que juzga la adecuación de las estrategias de acción política "que en principio considerábamos éticamente correctas" con "otros principios que también defendemos, lo cual debería llevarnos a revisar y rediseñar nuestras creencias" (Pérez, 2021, p. 525). Para cerrar estas reflexiones y dar lugar a los trabajos del dossier, cito estas palabras de Pérez, que suscribo:

Vivimos en tiempos muy complejos, en los que múltiples tipos de sujeción y de violencia nos atraviesan de distintas formas. No podemos seguir pensando en una sola manera de hacer política, una sola vía para "militar", o una sola forma de interpretar los problemas sociales. Ante problemas complejos, multicausales y dinámicos, no podemos responder con estrategias unidimensionales (Pérez, 2021, p. 535).

\section{Los trabajos de este dossier}

Los desafíos de la participación política en nuestros contextos democráticos en épocas de desdemocratización nos motivaron a convocar trabajos para este dossier. La mesa redonda (en castellano y francés) "Participación política, movimientos sociales y desafíos de la política contemporánea" versa directamente sobre estos desafíos. En ella, Moira Pérez y Joice Barbosa Becerra convocaron a Silvana Tapia Tapia (Ecuador), Abdourahmane Seck (Senegal) y Verónica Figueroa Huencho (Wellmapu), colegas del trabajo académico que desarrollan un activismo político y comunitario. Este intercambio es muy fructífero para quienes nos interesamos por "el escenario actual y los desafíos de la participación o acción política desde los movimientos de transformación social de distintas regiones del Sur global" y la "tensión entre los compromisos institucionales y la política radical".

Los artículos del dossier versan sobre diferentes aspectos de la participación política en diferentes niveles de análisis. Los cuatro primeros artículos se concentran en aspectos conceptuales y problemáticos, mientras que los últimos tres en la tematización de la participación democrática en autores del canon filosófico occidental. Así, Julia Gabriela Smola y Paula Leonor Hunziker escribieron "Participación política y libertad del pueblo: apuntes para pensar el republicanismo arendtiano en las disputas del presente", texto en el que recuperan aspectos del republicanismo arendtiano generalmente dejados de lado, según las autoras, en los debates contemporáneos, especialmente el concepto de pueblo. José Luis Galimidi se concentra en Hobbes y en "Recelo y admisión del elemento democrático en el Leviatán de Hobbes" analiza con profundidad la coexistencia paradójica en el pensamiento hobbesiano de un momento constituyente del Estado que es un acto de máxima libertad con el establecimiento a partir de él de una soberanía absoluta que obtura la participación ciudadana en el gobierno. En "Demostración, democracia intermitente y sorteo. Tres respuestas de Rancière al problema de la participación política", Alfredo Sánchez Santiago repone por su parte la complejidad del tratamiento del autor francés de la participación política, con énfasis en la herramienta del sorteo, para analizar sus aportes a los problemas del presente.

En cuanto a los artículos centrados en temas y problemas filosóficos de la participación política, contamos en primer lugar con "Retrospectivas de la interseccionalidad a partir de la resistencia desde los márgenes", de Fabiana Parra y Lucía Busquier. En este texto, las autoras trazan una genealogía política de la noción de interseccionalidad, tan difundida hoy en la academia y en diferentes activismos, que la conecta intrínsecamente con las luchas y demandas históricas concretas de la Colectiva del Río Combahee [Combahee River Collective] y de la Alianza de Mujeres del Tercer Mundo [Third World Women's Alliance]. Proponen luego que esta recuperación de la genealogía crítica de la interseccionalidad nos ayuda a contrarrestar su despolitización, neutralización y simplificación en los debates contemporáneos. En "What is Left for Critique? On the Perils of Innocence in Neoliberal Times", Paulo Ravecca y Elizabeth Dauphinee se concentran en los efectos de lo que llaman "apegos a la inocencia" en la academia y en la política. El texto detecta modos en los que la inocencia presente en diversas manifestaciones intelectuales impide que individuos y grupos confronten su 
propia participación en la opresión y analiza cómo el cultivo de un "yo-inocente" es recompensado en la academia y en el activismo en un proceso de reapropiación neoliberal de la política progresista que mantiene intacta la lógica de poder vigente. Proponen finalmente que "la inocencia no es una condición para nuestra participación en la vida política”. Ser conscientes de esto propiciaría una forma alternativa de encuentro que nos permitiría superar nuestros apegos a la inocencia.

Juan Marco Vaggione es autor de "La instrumentalización de la 'ideología de género' en las democracias contemporáneas". En este artículo, Vaggione propone que el uso del giro "ideología de género" permite rastrear las dimensiones públicas más importantes del neoconservadurismo en América Latina para echar luz sobre modos específicos de participación política de los conservadurismos religiosos en la región. Por último, en "Populismo, (post) hegemonía y democracia: repensar el populismo sin hegemonía" David Alejandro Valencia se dedica a analizar críticas al tratamiento de la hegemonía en la obra de Laclau para pensar la implementación de un populismo sin hegemonía que sería más proclive a formas democráticas de participación política.

El dossier incluye además un artículo de una autora invitada, Cristina Lafont, "Los minipúblicos deliberativos y la concepción populista de la representación como encarnación", y una traducción del texto "Epistemología de la Democracia" de Elizabeth Anderson. ${ }^{15}$ Lafont se ocupa de estudiar las propuestas de los minipúblicos deliberativos y su capacidad para superar los problemas que genera la distancia en la representación política en los sistemas partidarios tradicionales. La autora sostiene que la noción de representación que manejan por lo general estos diseños institucionales se asemeja a la idea de una "encarnación" del pueblo que Lafont asocia con el populismo. La representación como encarnación tiene efectos desdemocratizantes y por ello la autora propone una forma de entender la relación entre quienes participan de los minipúblicos y la ciudadanía que evita esos problemas. Por su parte, el trabajo de Anderson se concentra en las capacidades epistémicas de las instituciones democráticas. La autora evalúa tres modelos epistémicos de la democracia, i. e., el Teorema del Jurado de Condorcet, el Teorema de 'Diversidad supera Habilidad' y el modelo experimentalista de Dewey, para defender la superioridad de este último en su capacidad de dar cuenta de las tres notas constitutivas de la democracia, a saber: "la diversidad epistémica de los participantes, la interacción de la votación con el debate y los mecanismos de retroalimentación como las elecciones periódicas y las protestas". Un aporte interesante del artículo de Anderson es el modo en el que ella ilustra esto con un estudio de caso de "grupos forestales comunitarios en el Asia meridional, cuyas capacidades epistémicas se han visto perjudicados por la supresión de la participación de las mujeres".

\section{Bibliografía}

Anderson, Elizabeth (2010). The imperative of integration [El imperativo de la inclusión], Princeton, Princeton University. Berlin, Isaiah (1958). Two concepts of liberty [Dos conceptos de Libertad]. En Liberty. Incorporating Four Essays on Liberty, (pp. 166-217). Oxford University.

Bertomeu, María Julia (2021). Reflexiones republicanas sobre la libertad y la dominación. Conceptos y actores. En M. Marey (Ed.), Teorías de la república y prácticas republicanas (pp. 35-57). Herder.

Biglieri, Paula y Cadahia, Luciana (2021). Siete ensayos sobre populismo. Herder.

Condorcet, Marie-Jean-Antoine Nicolas de Caritat (1785). Essai sur l'application de l'analyse à la probabilité des décisions rendues à la pluralité des voix [Ensayo sobre la aplicación del análisis a la probabilidad de las decisiones tomadas por pluralidad de voces]. l'Imprimerie Royale.

Constant, Benjamin (1819), "De la liberté des Anciens comparée à celle des Modernes, discours prononcé à l'Athénée Royal de Paris" [De la libertad de los antiguos comparada con la de los modernos. Discurso pronunciado en el Ateneo de París], K. Kloocke y P. Delbouille, P., (eds.). OEuvres complètes. XV: Brochures politiques (1819-1821) [Obras completas. Folletos políticos (1819-1821)] (pp. 292-311). Walter de Gruyter.

Elster, Jon (1989). Self-realisation in work and politics: the Marxist conception of the good life [Autorrealización en el trabajo y en la política: la concepción marxista de la buena vida]. En J. Elster y K. O. Moene (Eds.), Alternatives to capitalism. Studies in Marxism and social theory [Alternativas al capitalismo. Estudios en marxismo y teoría social] (pp. 127-58). Cambridge University-Editions de la Maison des Sciences de l'Homme.

hooks, bell (1984). Feminist theory. From margin to center [Teoría feminista. De los márgenes al centro]. Pluto.

Lafont, Cristina (2019). Democracy without shortcuts: A participatory conception of deliberative democracy [Democracia sin atajos: una concepción participativa de la democracia deliberativa]. Oxford University.

Mahmood, Saba (2012). The politics of piety [Políticas de la Piedad]. Princeton University.

Marey, Macarena (2012). Breves reflexiones sobre el desafío del activista a la política deliberativa: el buen deliberativista no siempre delibera. Discusiones Filosóficas, 13(20), 187-207. http://www.scielo. org.co/scielo.php?script=sci_arttext\&pid=S0124-61272012000100010

Meiksins Wood, Ellen (1995). Democracy against capitalism. Renewing historical materialism [La democracia contra el capitalismo. Renovando el materialismo histórico]. Cambridge University. 
Mills, Charles W. (1997). The racial contract [El contrato racial]. Cornell University.

Pérez, Moira (2021). Interseccionalidad y estrategias feministas de reivindicación de derechos: un ejercicio de equilibrio reflexivo. En AA.VV. (Eds.), Tratado de géneros, derechos y justicia: políticas públicas y multidisciplina (pp. 523537). Rubinzal Culzoni.

Radi, Blas (2021). Pugna de derechos, injusticia y legalismo: una aproximación no ideal al derecho a la identidad de género en Argentina. Tesis de Licenciatura en Filosofía, Departamento de Filosofía, Facultad de Filosofía y Letras, Universidad de Buenos Aires.

Rosenberg, Arthur (2006). Democracia y lucha de clases en la antigüedad. El viejo topo.

Schumpeter, Joseph (1942). Capitalism, socialism, and democracy [Capitalismo, socialismo y democracia]. Harper Colophon.

Talisse, Robert (2005). Deliberativist responses to activist challenges. A continuation of Young's dialectic. Philosophy and Social Criticism, 31(4), 423-44. https://doi.org/10.1177/0191453705052978

Youg, Iris Marion (2000). Inclusion and democracy [Inclusión y democracia]. Oxford University.

Young, Iris Marion (2001). Activist challenges to deliberative democracy. Political Theory, 29(5), 670-90. https://www. jstor.org/stable/3072534

Young, Iris Marion (2011). Responsibility for justice [Responsabilidad por la justicia]. Oxford University. 